\title{
Failure of the Normal Ureagenic Response to Amino Acids in Organic Acid-loaded Rats
}

\author{
PROPOSED MECHANISM FOR THE HYPERAMMONEMIA OF PROPIONIC
} AND METHYLMALONIC ACIDEMIA

\author{
Peter M. Stewart and Mackenzie Walser, Department of Pharmacology and \\ Experimental Therapeutics and Department of Medicine, Johns Hopkins University \\ School of Medicine, Baltimore, Maryland 21205
}

\begin{abstract}
A B S T RACT Propionic and methylmalonic acidemia are both known to be associated with hyperammonemia. Rats injected with 10 or $20 \mathrm{mmol} / \mathrm{kg}$ of propionate or $20 \mathrm{mmol} / \mathrm{kg}$ of methylmalonate, along with $1.5 \mathrm{~g} / \mathrm{kg}$ of a mixture of amino acids, developed severe hyperammonemia, whereas rats administered the same dosages of acetate did not. In vitro, neither propionyl nor methylmalonyl CoA affected the activity of carbamyl phosphate synthetase I, ornithine transcarbamylase, nor the activation constant $\left(K_{\mathrm{A}}\right)$ of carbamyl phosphate synthetase I for $\mathrm{N}$-acetyl glutamate. Furthermore, rats injected with propionate showed no alteration of liver amino acid concentrations, which could explain impaired ureagenesis. Animals injected with methylmalonate showed an increase in both citrulline and aspartate, suggesting that argininosuccinic acid synthetase may also have been inhibited. Liver ATP levels were unchanged. Citrullinogenesis, measured in intact mitochondria from livers of injected animals, was reduced $20-25 \%$ by $20 \mathrm{mmol} / \mathrm{kg}$ of propionate or methylmalonate (compared with acetate). This effect was attributable to an impairment in the normal rise of liver $\mathrm{N}$-acetyl glutamate content after amino acid injection. Thus, carbamyl phosphate synthetase I activation was reduced. Liver levels of acetyl $\mathrm{CoA}$ and free $\mathrm{CoA}$ were reduced. Levels of unidentified acyl CoA derivatives rose, presumably reflecting the accumulation of propionyl and methylmalonyl CoA. Thus, the principal mechanism for hyperammonemia induced by these acids is depletion of liver $\mathrm{N}$-acetyl glutamate, which is in turn attributable to depletion of acetyl CoA and/or
\end{abstract}

A preliminary report of this work appeared in 1980. Clin. Res. 28: 407A. (Abstr.)

Received for publication 10 March 1980 and in revised form 2 May 1980. competitive inhibition by propionyl and methylmalonyl CoA of $\mathrm{N}$-acetyl glutamate synthetase. Injection of methylmalonate may also have an additional inhibitory effect on argininosuccinic acid synthetase.

\section{INTRODUCTION}

Hyperammonemia is associated with metabolic defects in the metabolism of propionic and methylmalonic acids (1). A correlation between the levels of propionate and ammonia in the blood in children with propionic acidemia (2) has been demonstrated. These organic acids could affect ureagenesis in many ways, any or all of which could explain the hyperammonemia. Inhibition of ureagenesis by propionate has been demonstrated in liver slices (3), and citrullinogenesis in isolated mitochondria is impaired by addition of propionate $(4,5)$. These effects have been ascribed to reduction of energy supply in both slices (3) and mitochondria (5), resulting in decreases in carbamyl phosphate synthetase I and argininosuccinic acid synthetase activity because the reduction in ureagenesis correlates with a fall in ATP levels.

Another possible explanation is the suggestion of Bachmann (6) that the known inhibition of $N$-acetyl glutamate synthetase by propionyl $\mathrm{CoA}(7)$ or production by this enzyme of a relatively ineffectual activator, $N$-propionyl glutamate (8), may impair carbamyl phosphate synthetase I activation, thereby leading to hyperammonemia. We have recently reported that rapid changes in $\mathrm{N}$-acetyl glutamate mediate the short-term regulation of ureagenesis by activating carbamyl phosphate synthetase I (9). In support of Bachmann's suggestion, a reduction in $\mathrm{N}$-acetyl glutamate content in mitochondria incubated with propionate and glutamate has been described (10). Furthermore, Coude et al. (11) 
have examined in detail the competitive inhibition by propionyl CoA of $N$-acetyl glutamate synthetase, and have confirmed that $N$-propionyl glutamate is an activator, albeit a weak one, of carbamyl phosphate synthetase I.

In a recent preliminary report (12), evidence for another mechanism has been presented. Propionyl CoA added to liver homogenate reduced carbamyl phosphate synthetase I activity. However, other workers found little inhibition of citrulline synthesis in intact mitochondria by propionate when ATP was supplied exogenously (5). Under these conditions, propionyl CoA would be in high concentration. Propionate has been shown to be without effect on the enzyme (3).

Another possible explanation for the hyperammonemia of methylmalonic acidemia was recently suggested by Walajtys-Rode et al. (13). They found that $\alpha$-ketoisovalerate inhibited ureagenesis in isolated rat liver hepatocytes. They attributed this effect to an impairment in the generation of aspartate, one of the nitrogen donors for urea synthesis. Acetyl CoA levels fell as other acyl CoA derivatives formed in the course of $\alpha$-ketoisovalerate metabolism rose. Acetyl $\mathrm{CoA}$ is an obligatory activator for pyruvate carboxylase (14), the major anapleurotic reaction for the four-carbon pool in the liver. A reduction in the activity of this enzyme through a fall in acetyl CoA levels would be expected to impair aspartate generation. Furthermore, methylmalonate derived from $\alpha$-ketoisovalerate may have inhibited malate transport (15), an effect that could further impair aspartate synthesis. Evidence has been presented that argininosuccinic acid synthetase is the ratecontrolling enzyme in ureagenesis (16-18). If this is correct, a reduction in the availability of aspartate, one of the two substrates for this reaction, would impair ureagenesis.

We present here results of studies of the mechanisms whereby ureagenesis is impaired in animals administered loads of propionate or methylmalonate.

\section{METHODS}

Female rats obtained from ARS Sprague-Dawley, Madison, Wis., were fed a diet containing $14 \%$ protein for at least $7 \mathrm{~d}$ before use. Organic acids were administered by intraperitoneal injection as sodium salts adjusted to $\mathrm{pH} 7.2$ in a volume of 4 $\mathrm{ml} / 200 \mathrm{~g}$ body wt. A complete amino acid mixture (19) ("Mix $\mathrm{A}^{\prime \prime}$ ) in doses of $0.5,1$, or $1.5 \mathrm{~g} / \mathrm{kg}$ was administered $10 \mathrm{~min}$ later by intraperitoneal injection in a $5-\mathrm{ml}$ vol of $150 \mathrm{mM}$ $\mathrm{NaCl} / 200 \mathrm{~g}$ body wt. In some experiments, an amino acid mixture ("Mix B") with higher proportions of short-chain amino acids was used (glutamine, asparagine, and glutamate each reduced 50\%; alanine, serine, and glycine increased to $13.4,9.4$, and $13.52 \mathrm{~g} / 100 \mathrm{~g}$ of amino acid mixture, respectively). The animals were anesthetized with ether; portions of blood and liver were processed and analyzed at various time intervals as previously described (9). ATP, malate, and $\alpha$-ketoglutarate were measured according to the method of Lamprecht and Trautschold (20), Hohorst (21), and Berg- meyer and Bernt (22), respectively. CoA and its acylated derivatives were determined in the perchloric acid supernate of freeze-clamped liver by the method of Kondrup and Grunnet (23). Measurements of $\mathrm{N}$-acetyl glutamate, $\mathrm{NH}_{3}$, amino acids and carbamyl phosphate synthetase I activity, and mitochondrial preparation were performed by methods detailed elsewhere (9). Ornithine transcarbamylase activity in disrupted mitochondria was measured using the method of McGivan et al. (24).

Synthesis of $N$-propionyl glutamate was carried out by propionylation of glutamate in alkaline solution (25). Recovery experiments were performed by enzymatic determination of glutamate after hydrolysis with acylase I. In the presence of a slight excess of propionic anhydride, the conversion to $\mathrm{N}$-propionyl glutamate was stoichiometric. Isolation of $\mathrm{N}$ acetyl and $N$-propionyl glutamate from livers was carried out by the method of Shigesada et al. (26), with the exception that the final chromatographic step was omitted and replaced by hydrolysis of the acylated derivatives and paper chromatography using $n$-butanol:acetic acid/water, 20:1:0.5. This adaptation resulted in improved resolution of the compounds of interest from malate and $\alpha$-ketoglutarate in particular. Recoveries of $N$-acetyl and $N$-propionyl glutamate were 73-78\%.

[U-C ${ }^{14}$ glutamate was obtained from Amersham Corp., Arlington Heights, Ill., and purified by paper chromatography in n-butanol:acetic acid:water, 20:1:0.5 before use. Acylase I, phosphotransacetylase and ornithine transcarbamylase were purchased from Sigma Chemical Co., St. Louis, Mo. Other enzymes were purchased from Boehringer Mannheim Biochemicals, Indianapolis, Ind.

\section{RESULTS}

Effects of organic acids on blood ammonia. In rats administered $1.5 \mathrm{~g} / \mathrm{kg}$ of intraperitoneal amino acids, the time course of blood ammonia after intraperitoneal injection of $20 \mathrm{mmol} / \mathrm{kg}$ of acetate compared with 10 or $20 \mathrm{mmol} / \mathrm{kg}$ of propionate is shown in Fig. 1. Only a small increase in blood ammonia is seen after injection of amino acids in acetate-treated animals. In animals injected with either dose of propionate, blood ammonia increased significantly at the earliest time interval, $10 \mathrm{~min}$ after injection of propionate, and peaked $25 \mathrm{~min}$ after propionate ( $15 \mathrm{~min}$ after injection of amino acids).

The dependence of this response on amino acid dosage is shown in Fig. 2. Again, controls received $20 \mathrm{mmol} / \mathrm{kg}$ of acetate. Only the largest dose of propionate $(20 \mathrm{mmol} / \mathrm{kg})$ caused hyperammonemia in rats not administered amino acids. With increasing dosage of amino acids, increasing hyperammonemia is seen at doses of propionate of 10 and $20 \mathrm{mmol} / \mathrm{kg}$. A lower dose $(5 \mathrm{mmol} / \mathrm{kg})$ of propionate had no effect on blood ammonia, even at $1.5 \mathrm{~g} / \mathrm{kg}$ of amino acids.

Methylmalonate at a dose of $10 \mathrm{mmol} / \mathrm{kg}$ did not cause a significant increase in blood ammonia in rats administered $1.5 \mathrm{~g} / \mathrm{kg}$ of amino acids, but did at a dose of $20 \mathrm{mmol} / \mathrm{kg}$.

No obvious clinical effects were produced by these large doses of organic acids, except lethargy coinciding with the highest levels of blood ammonia, and receding as ammonia fell towards normal. 


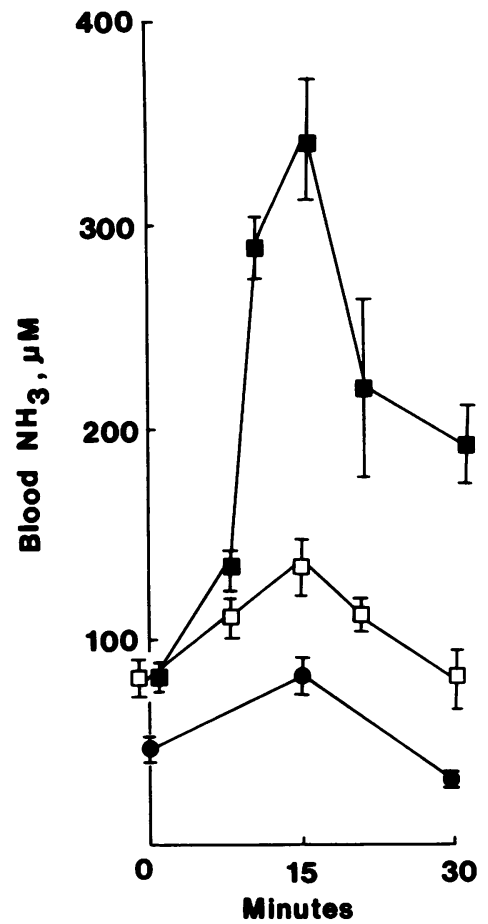

Figure 1 The effect of $10 \mathrm{mmol} / \mathrm{kg}$ of propionate (open squares), $20 \mathrm{mmol} / \mathrm{kg}$ propionate (closed squares), and 20 $\mathrm{mmol} / \mathrm{kg}$ acetate (closed circles) on the time course of blood ammonia. An intraperitoneal load of $1.5 \mathrm{~g} / \mathrm{kg}$ body wt of an amino acid mixture was administered $10 \mathrm{~min}$ after the injection of organic acids. The amino acid injection is indicated as time zero on the figure. Means \pm SEM., $n=4-7$.

Dependence of carbamyl phosphate synthetase I activity on energy source. As noted above, there is evidence that propionate interferes with energy production within the mitochondria, thereby lowering the activity of carbamyl phosphate synthetase I. To examine this possibility, citrullinogenesis in organic acid- and amino acid-loaded rats was determined in the absence of exogenous ATP.

When succinate and rotenone replaced ATP, thus leading to endogenously produced ATP, carbamyl phosphate synthetase I activity of intact mitochondria isolated from rats administered $1.5 \mathrm{~g} / \mathrm{kg}$ of amino acids was $24.6 \pm 0.4 \mathrm{nmol} / \mathrm{min} / \mathrm{mg}$ of mitochondrial protein after $20 \mathrm{mmol} / \mathrm{kg}$ of acetate and $18.2 \pm 1.3 \mathrm{nmol} /$ min after $20 \mathrm{mmol} / \mathrm{kg}$ of propionate (SEM, $n=5$ ). This $26 \%$ reduction is very close to the reduction seen when exogenous ATP was used (24\%, Fig. 3).

Effect of organic acids on substrate levels in the liver. Ureagenesis requires a coordinate supply of aspartate as well as carbamyl phosphate. Pyruvate carboxylase requires acetyl CoA for its activation (14). The activation constant $\left(K_{\mathrm{A}}\right)^{1}$ for propionyl $\operatorname{CoA}$ is

${ }^{1}$ Abbreviation used in this paper: $K_{\mathrm{A}}$, activation constant.

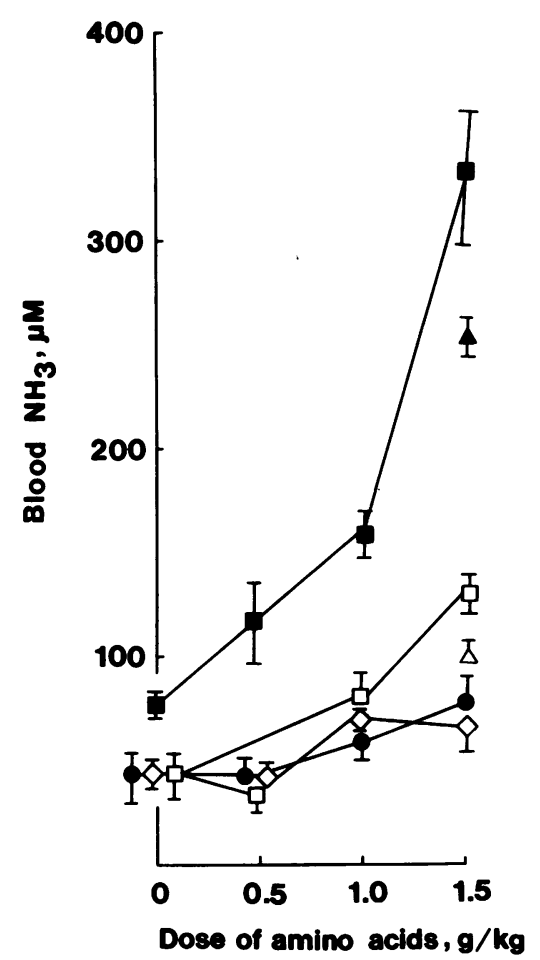

FIGURE 2 The effect of varying doses of an amino acid mixture administered after prior loading with organic acids on blood $\mathrm{NH}_{3}$. Symbols as in Fig. 1 with the addition of propionate, $5 \mathrm{mmol} / \mathrm{kg}$ (open diamonds), methylmalonate, $10 \mathrm{mmol} / \mathrm{kg}$ (open triangle), and $20 \mathrm{mmol} / \mathrm{kg}$ (closed triangle). Blood was collected for $\mathrm{NH}_{3}$ determinations 15 min after the amino acid mixture and $25 \mathrm{~min}$ after the organic acid load. Means \pm SEM., $n=4-7$.

threefold higher (14), and methylmalonyl CoA is a competitive inhibitor of acetyl CoA (27). Furthermore, methylmalonate, a product of propionate metabolism, inhibits mitochondrial malate transport (15). Hence, aspartate synthesis may be impaired or its availability in the cytosol may be decreased. As shown in Table I, propionate has no effect on hepatic concentrations of aspartate or glutamate. Furthermore, glutamine, malate, and $\alpha$-ketoglutarate were unaltered by propionate.

To attempt to provoke a deficiency in aspartate and/ or glutamate in the presence of propionate, these experiments were repeated using an amino acid mixture lower in four-carbon amino acids. Again, hepatic aspartate levels were unaffected (Table I). Thus, for reasons not apparent, it appears that pyruvate carboxylase flux is not sufficiently inhibited by propionate treatment to result in a limitation in the availability of either aspartate or glutamate.

Methylmalonate at a dose of $10 \mathrm{mmol} / \mathrm{kg}$ significantly reduced liver glutamate and aspartate after the injection of either of the two amino acid mixtures, as might be expected from the above considerations. However, after $20 \mathrm{mmol} / \mathrm{kg}$ of methylmalonate, glutamate and 


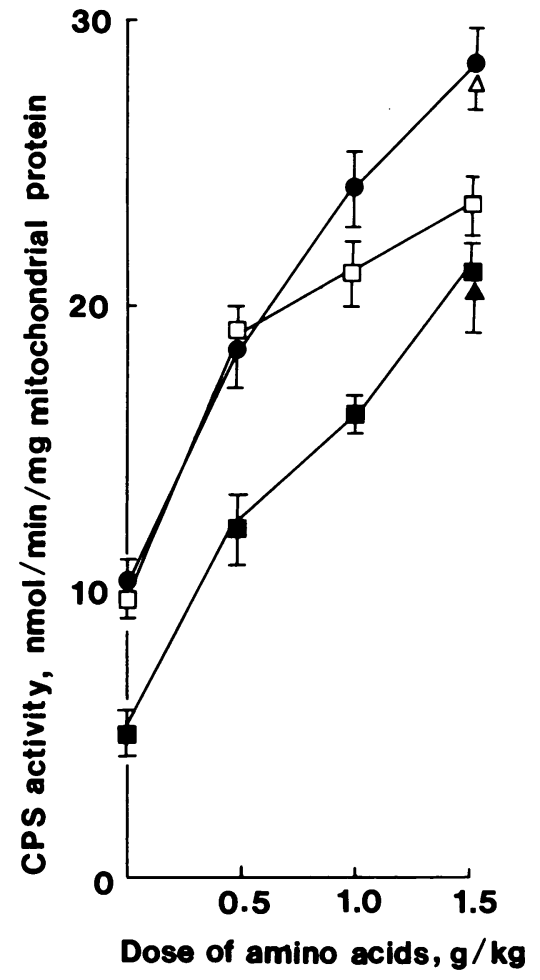

Figure 3 The effect of varying doses of an amino acid mixture on carbamyl phosphate synthetase I (CPS) activity in intact mitochondria isolated from livers of these animals. Symbols as in Fig. 2. Means \pm SEM., $n=4-6$. aspartate were both increased. Conceivably, these changes may have been secondary to inhibition of argininosuccinic acid synthetase, as considered below.

Effect of organic acids on hepatic ATP concentrations. ATP levels in the livers of propionate- or methylmalonate-injected rats were the same as those in acetate-injected animals, whether or not amino acids were injected (Table I). Because about one-third of hepatic cellular ATP is mitochondrial and two-thirds is in the cytosol (28), significant changes within the mitochondrial compartment may not be detected. Nevertheless, these results contrast with the reported decrease in ATP levels of mitochondria exposed in vitro to propionate $(4,5)$.

Urea cycle intermediates in the liver. To explore the possibility that these organic acids inhibited reactions of the urea cycle downstream from carbamyl phosphate synthetase I, we measured arginine, citrulline, and ornithine levels in the livers of rats given $1.5 \mathrm{~g} / \mathrm{kg}$ of amino acids intraperitoneally. As shown in Table II, propionate at either 10 or $20 \mathrm{mmol} / \mathrm{kg}$ did not alter the tissue levels of these three amino acids when compared with acetate at the same doses. Methylmalonate, however, caused a large and significant increase in citrulline levels, particularly at the larger dose. This finding suggests that methylmalonate may have inhibited argininosuccinic acid synthetase. There was also a small increase in arginine levels.

The levels observed with acetate are not statistically

TABLE I

Effect of Organic Acid Injections on Metabolites in Livers of Rats Administered Varying Mixtures of Intraperitoneal Amino Acids*

\begin{tabular}{|c|c|c|c|c|c|c|c|c|c|c|c|c|c|}
\hline \multirow{2}{*}{$\begin{array}{l}\text { Organic acid } \\
\text { injection }\end{array}$} & \multicolumn{4}{|c|}{ No amino acid } & \multicolumn{6}{|c|}{ Amino acid mix A, $1.5 \mathrm{~g} / \mathrm{kg}$} & \multicolumn{3}{|c|}{ Amino acid mix $B, 1.5 \mathrm{~g} / \mathrm{kg}$} \\
\hline & Glut & Gln & Asp & ATP & Glu & Gln & Asp & ATP & $\alpha \mathrm{KG}$ & Mal & Glu & Gln & Asp \\
\hline & \multicolumn{4}{|c|}{$\mu \mathrm{mol} / \mathrm{g}$} & \multicolumn{6}{|c|}{$\mu \mathrm{mol} / \mathrm{g}$} & \multicolumn{3}{|c|}{$\mu \mathrm{mol} / \mathrm{g}$} \\
\hline \multicolumn{14}{|l|}{ Acetate } \\
\hline \multirow[t]{2}{*}{$10 \mathrm{mmol} / \mathrm{kg}$} & 2.42 & 4.02 & 1.33 & - & 3.58 & 3.23 & 3.18 & 2.73 & 0.16 & 0.47 & 3.52 & 3.47 & 3.33 \\
\hline & \pm 0.11 & \pm 0.37 & \pm 0.18 & & \pm 0.22 & \pm 0.13 & \pm 0.14 & \pm 0.18 & \pm 0.02 & \pm 0.06 & \pm 0.09 & \pm 0.28 & \pm 0.17 \\
\hline \multirow[t]{2}{*}{$20 \mathrm{mmol} / \mathrm{kg}$} & 2.52 & 3.89 & 1.40 & 2.40 & 3.56 & 3.60 & 3.44 & 2.66 & 0.14 & 0.42 & 3.48 & 3.29 & 3.24 \\
\hline & \pm 0.13 & \pm 0.19 & \pm 0.07 & \pm 0.11 & \pm 0.22 & \pm 0.23 & \pm 0.15 & \pm 0.11 & \pm 0.02 & \pm 0.09 & \pm 0.09 & \pm 0.21 & \pm 0.23 \\
\hline \multicolumn{14}{|l|}{ Propionate } \\
\hline \multirow{2}{*}{$10 \mathrm{mmol} / \mathrm{kg}$} & 2.43 & 4.16 & 1.16 & - & 3.48 & 3.23 & 3.21 & 2.55 & 0.13 & 0.40 & 3.29 & 2.88 & 3.48 \\
\hline & \pm 0.03 & \pm 0.16 & \pm 0.09 & & \pm 0.18 & \pm 0.11 & \pm 0.18 & \pm 0.08 & \pm 0.04 & \pm 0.03 & \pm 0.11 & \pm 0.21 & \pm 0.16 \\
\hline \multirow[t]{2}{*}{$20 \mathrm{mmol} / \mathrm{kg}$} & 2.51 & 4.52 & 1.26 & 2.53 & 3.49 & 3.51 & 3.40 & 2.58 & 0.13 & 0.38 & 3.39 & 3.07 & 3.51 \\
\hline & \pm 0.09 & \pm 0.30 & \pm 0.09 & \pm 0.20 & \pm 0.07 & \pm 0.13 & \pm 0.11 & \pm 0.10 & \pm 0.04 & \pm 0.06 & \pm 0.15 & \pm 0.30 & \pm 0.13 \\
\hline \multicolumn{14}{|l|}{ Methylmalonate } \\
\hline \multirow[t]{2}{*}{$10 \mathrm{mmol} / \mathrm{kg}$} & 2.30 & 3.80 & 1.24 & - & $2.96 \$$ & 3.42 & $2.33^{\prime \prime}$ & 2.60 & 0.10 & 0.38 & $2.80 \$$ & 3.60 & 2.07 \\
\hline & \pm 0.10 & \pm 0.22 & \pm 0.06 & & \pm 0.04 & \pm 0.43 & \pm 0.07 & \pm 0.17 & \pm 0.02 & \pm 0.03 & \pm 0.23 & \pm 0.09 & \pm 0.16 \\
\hline \multirow[t]{2}{*}{$20 \mathrm{mmol} / \mathrm{kg}$} & 2.62 & 3.73 & 1.43 & 2.40 & 4.00 & 3.84 & $4.41 \%$ & 2.48 & 0.11 & 0.45 & 3.839 & 2.99 & $4.20 \%$ \\
\hline & \pm 0.13 & \pm 0.34 & \pm 0.06 & \pm 0.09 & \pm 0.09 & \pm 0.32 & \pm 0.41 & \pm 0.14 & \pm 0.04 & \pm 0.11 & \pm 0.10 & \pm 0.13 & \pm 0.31 \\
\hline
\end{tabular}

* Means \pm SEM, $n=5-6$

I Abbreviations used in this table: Glu, glutamate; Gln, glutamine; Asp, aspartate; $\alpha \mathrm{KG}, \alpha$-ketoglutarate; Mal, malate.

$\$$ Significantly different from mean in rats injected with the same dose of acetate, $P<0.02$.

"Significantly different from mean in rats injected with the same dose of acetate, $P<0.01$.

I Significantly different from mean in rats injected with the same dose of acetate, $P<0.05$. 
TABLE II

Urea Cycle Intermediates in Livers of Rats Injected with Organic Acids Followed by an Amino Acid Mixture*

\begin{tabular}{|c|c|c|c|c|c|c|}
\hline & Acetate & Propionate & Methylmalonate & Acetate & Propionate & Methylmalonate \\
\hline & \multicolumn{3}{|c|}{$10 \mathrm{mmol} / \mathrm{kg}$} & \multicolumn{3}{|c|}{20 mmollkg } \\
\hline Arginine, $\mu \mathrm{mol} / \mathrm{g}$ & $\begin{array}{r}0.209 \\
\pm 0.013\end{array}$ & $\begin{array}{r}0.210 \\
\pm 0.015\end{array}$ & $\begin{array}{r}0.189 \\
\pm 0.011\end{array}$ & $\begin{array}{r}0.204 \\
\pm 0.015\end{array}$ & $\begin{array}{r}0.205 \\
\pm 0.013\end{array}$ & $\begin{array}{r}0.268 \ddagger \\
\pm 0.011\end{array}$ \\
\hline Citrulline, $\mu \mathrm{mol} / \mathrm{g}$ & $\begin{array}{r}0.068 \\
\pm 0.025\end{array}$ & $\begin{array}{r}0.068 \\
\pm 0.012\end{array}$ & $\begin{array}{c}0.133 \ddagger \\
\pm 0.014\end{array}$ & $\begin{array}{r}0.068 \\
\pm 0.017\end{array}$ & $\begin{array}{r}0.084 \\
\pm 0.019\end{array}$ & $\begin{array}{c}0.389 \downarrow \\
\pm 0.052\end{array}$ \\
\hline Ornithine, $\mu \mathrm{mol} / \mathrm{g}$ & $\begin{array}{r}0.616 \\
\pm 0.066\end{array}$ & $\begin{array}{r}0.650 \\
\pm 0.047\end{array}$ & $\begin{array}{r}0.747 \\
\pm 0.031\end{array}$ & $\begin{array}{r}0.659 \\
\pm 0.057\end{array}$ & $\begin{array}{r}0.635 \\
\pm 0.032\end{array}$ & $\begin{array}{r}0.713 \\
\pm 0.057\end{array}$ \\
\hline
\end{tabular}

* Means \pm SEM, $n=5-10$.

\Significantly different from acetate-treated rats, $P<0.01$.

different from those we have found previously in rats administered the same dose of amino acids but no organic acids (9).

Effect of organic acids and their CoA derivatives on the kinetic properties of carbamyl phosphate synthetase $I$ and ornithine transcarbamylase. As noted above, a recent in vitro study (12) has indicated that propionyl CoA inhibits carbamyl phosphate synthetase $I$ in liver homogenates. Table III shows the absence of any significant effect of propionate, methylmalonate, or their CoA derivatives on the $K_{\mathrm{A}}$ of carbamyl phosphate synthetase I for $\mathrm{N}$-acetyl glutamate, the maximal velocity of this enzyme, and the maximal velocity of ornithine transcarbamylase, assayed in disrupted mitochondria.

\section{TABLE III}

Effect of Propionate, Methylmalonate, and their CoA Derivatives Added In Vitro on the $K_{A}$ of $N$-Acetyl Glutamate, the $V_{\max }$ of Carbamyl Phosphate Synthetase I, and the $V_{\max }$ of Ornithine Transcarbamylase in Disrupted Liver Mitochondria

\begin{tabular}{|c|c|c|c|}
\hline \multirow[b]{2}{*}{ Addition } & \multirow{2}{*}{$\begin{array}{c}\boldsymbol{K}_{\mathbf{A}} \text { for } \\
N \text {-acetyl } \\
\text { glutamate }\end{array}$} & \multicolumn{2}{|c|}{$v_{\text {max }} *$} \\
\hline & & CPS & оTC \\
\hline & $m M$ & \multicolumn{2}{|c|}{ nmol/min/mg } \\
\hline None & 0.21 & 38 & 780 \\
\hline Propionate, $1 \mathrm{mM}$ & 0.23 & 43 & 810 \\
\hline Propionate, $10 \mathrm{mM}$ & 0.25 & 37 & 660 \\
\hline Propionyl CoA, $1 \mathrm{mM}$ & 0.22 & 34 & 690 \\
\hline Propionyl CoA, $10 \mathrm{mM}$ & 0.19 & 32 & 767 \\
\hline Methylmalonate, $10 \mathrm{mM}$ & 0.25 & 37 & 780 \\
\hline Methylmalonyl CoA, $1 \mathrm{mM}$ & 0.19 & 36 & 640 \\
\hline
\end{tabular}

Means, $n=2-7$.

* Abbreviations used in this table: CPS, carbamyl phosphate synthetase I; OTC, ornithine transcarbamylase; $V_{\max }$, maximum velocity.
Effects of organic acids on carbamyl phosphate synthetase I activity in intact mitochondria. Carbamyl phosphate synthetase $I$ is significantly reduced by $10 \mathrm{mmol} / \mathrm{kg}$ of propionate (as compared with 20 $\mathrm{mmol} / \mathrm{kg}$ of acetate) only in rats injected with the largest dose of amino acids ( $1.5 \mathrm{~g} / \mathrm{kg}$ ) (Fig. 3). However, $20 \mathrm{mmol} / \mathrm{kg}$ of propionate significantly reduced carbamyl phosphate synthetase I activity at all doses of amino acids, including zero.

Methylmalonate at a dose of $20 \mathrm{mmol} / \mathrm{kg}$ reduced carbamyl phosphate synthetase I activity significantly in rats injected with $1.5 \mathrm{~g} / \mathrm{kg}$ of amino acids, but had no effect at a dose of methylmalonate half as great.

Effect of organic acids on liver $\mathrm{N}$-acetyl glutamate concentration. The changes in $\mathrm{N}$-acetyl glutamate concentrations (Fig. 4) are similar to the changes in carbamyl phosphate synthesis I activity in the same animals (Fig. 3). As shown in Fig. 5, the relationship between these two variables in rats injected with all three of these organic acids is nearly identical to the relationship previously observed in rats administered amino acids alone at these same dosages (9). This suggests that the reduction in carbamyl phosphate synthetase I activity in propionate- and methylmalonate-treated animals compared with those treated with acetate is fully explained by the fall in $\mathrm{N}$-acetyl glutamate concentration.

Synthesis of N-acetyl and N-propionyl glutamate in vivo. To determine whether $N$-propionyl glutamate was formed in propionate-injected rats, and to assess the effect of propionate loads of $\mathrm{N}$-acetyl glutamate formation, an intraperitoneal load of arginine ( $3 \mathrm{mmol} / \mathrm{kg}$ ) was administered; $10 \mathrm{~min}$ later the rats were administered intraperitoneal $\left[{ }^{14} \mathrm{C}\right]$ glutamate. These conditions were chosen to maximize $\mathrm{N}$-acetyl glutamate synthetase activity and to minimize dilution of the labeled glutamate. Injection of arginine in similar amounts is known in increase $\mathrm{N}$-acetyl glutamate synthesis in vivo (29). $30 \mathrm{~min}$ after $\left[{ }^{14} \mathrm{C}\right]$ glutamate 


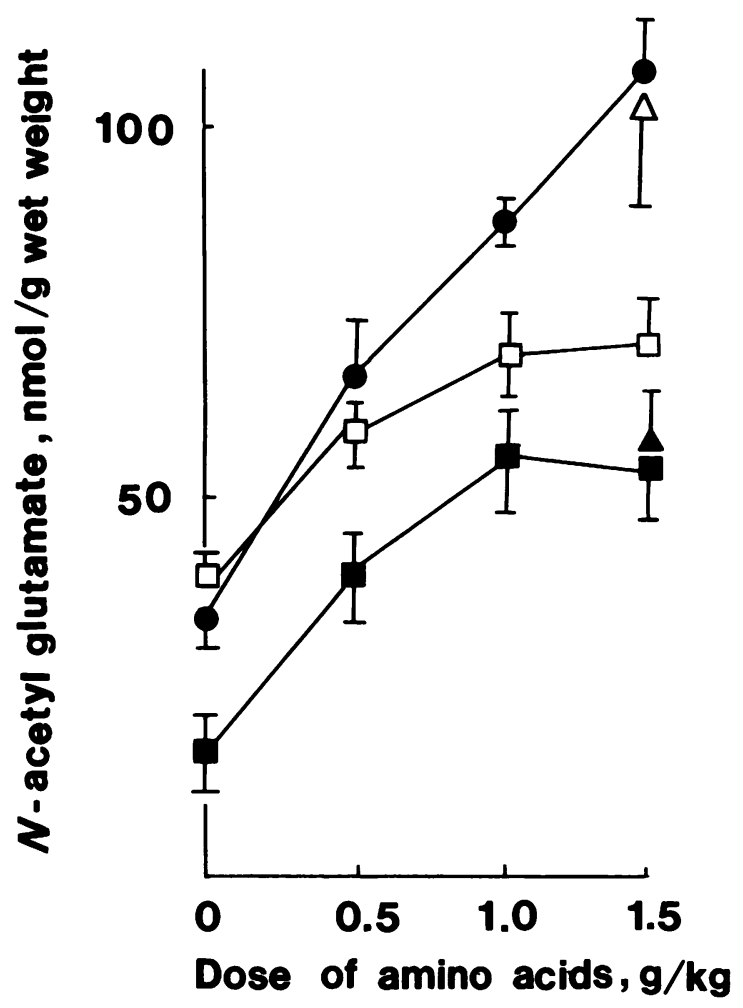

FIGURE 4 The effect of amino acid loads at varying doses on $N$-acetyl glutamate content of the liver. Symbols as in Fig. 2. Means \pm SEM., $n=4-6$.

injection, whole livers were analyzed for radioactivity in $\mathrm{N}$-acetyl and $\mathrm{N}$-propionyl glutamate. In rats administered acetate $20 \mathrm{mmol} / \mathrm{kg}, 1,974 \pm 250$ (SEM., $n$ =3) counts/min were found in $N$-acetyl glutamate and $11 \pm 13$ counts/min in $N$-propionyl glutamate (a value not significantly different from zero). In rats administered propionate $20 \mathrm{mmol} / \mathrm{kg}, 795 \pm 172$ (SEM., $n=3$ ) counts/min were found in $\mathrm{N}$-acetyl glutamate and $52 \pm 12$ counts/min in $N$-propionyl glutamate. Thus, propionate reduced $\mathrm{N}$-acetyl glutamate formation but led to the formation of only small amounts of $\mathrm{N}$-propionyl glutamate. Hence, this latter compound, its concentration being only $1 / 25$ that of $\mathrm{N}$-acetyl glutamate, cannot exert a significant effect on carbamyl phosphate synthetase I under these conditions.

Effect of organic acids on CoA compounds in the liver. The results are shown in Table IV. The total of all perchloric acid-soluble CoA compounds was scarcely altered after $20 \mathrm{mmol} / \mathrm{kg}$ of either propionate or methylmalonate. However, there were substantial reductions in both free and acetyl CoA, concomitantly with increases in unidentified acyl CoA derivatives. Presumably, propionyl and methylmalonyl CoA were major components of this unidentified fraction. The fall in acetyl CoA clearly could have been a factor contributing to reduction in $N$-acetyl glutamate levels.

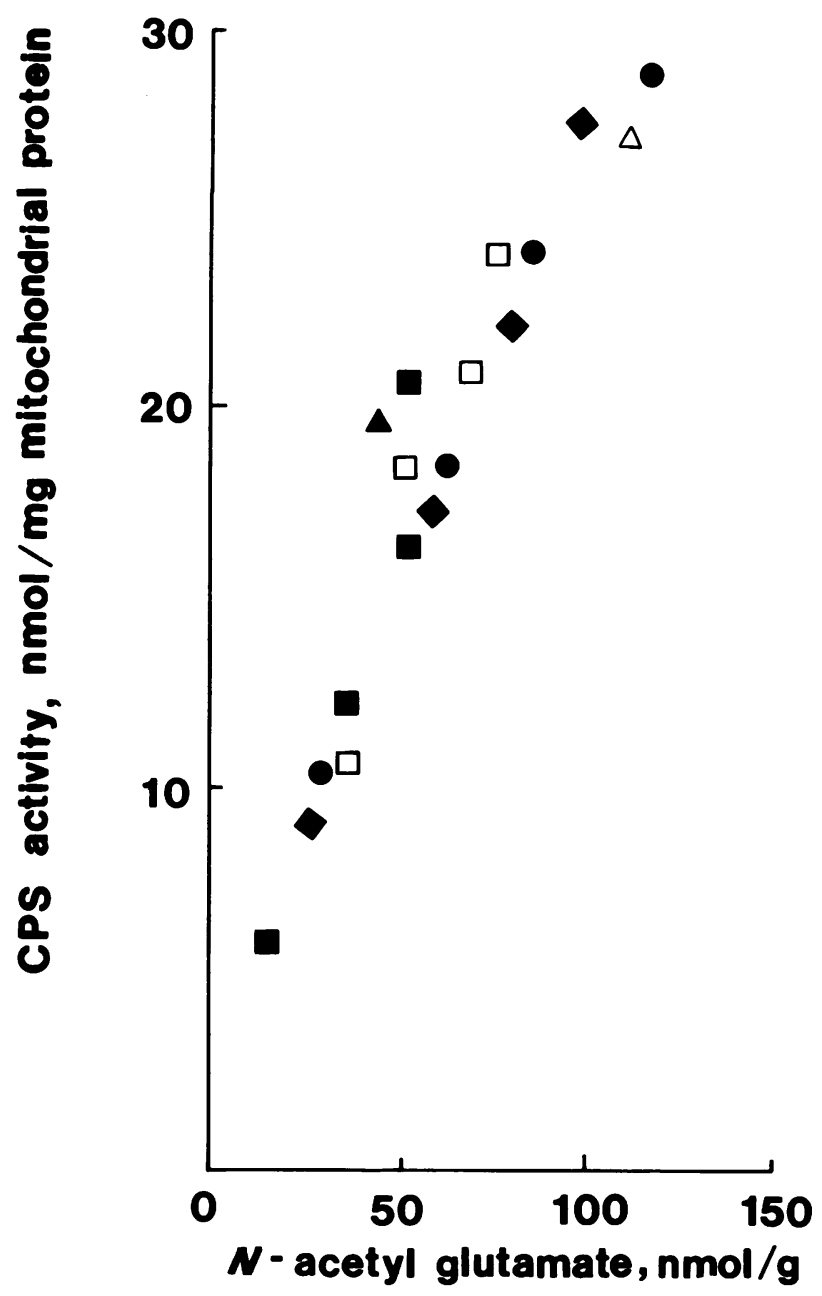

FIGURE 5 Dependence of carbamyl phosphate synthetase I (CPS) activity of intact mitochondria on liver $N$-acetyl glutamate content. Symbols as in Fig. 2 with the addition of closed triangles to indicate no organic acid injection; these data were obtained from reference 9 . Each point is the average of four to seven observations.

Likewise, accumulation of propionyl or methylmalonyl CoA could have competitively inhibited $\mathrm{N}$-acetyl glutamate synthetase.

\section{DISCUSSION}

These results show that the hyperammonemia seen in rats injected with large doses of propionate or methylmalonate is chiefly attributable to depletion of $\mathrm{N}$-acetyl glutamate, an obligatory activator of mitochondrial carbamyl phosphate synthetase I. Propionate had no other measured effects on liver that would have impaired ureagenesis; methylmalonate, however, altered the levels of both aspartate and citrulline, suggesting that its effects on ureagenesis may have been more complex. 
TABLE IV

CoA Compounds in the Liver after Organic Acid Injections

\begin{tabular}{lccc}
\hline \multirow{2}{*}{$\begin{array}{c}\text { CoA compounds, } \\
\text { nmol/g wet weight }\end{array}$} & \multicolumn{3}{c}{ Organic acid injected, $20 \mathrm{mmol} / \mathrm{kg}$} \\
\cline { 2 - 4 } & Acetate & Propionate & Methylmalonate \\
\hline $\begin{array}{c}\text { Total perchloric } \\
\text { acid soluble CoA }\end{array}$ & $70.7 \pm 5.9$ & $69.0 \pm 5.7$ & $79.1 \pm 4.9$ \\
CoASH & $39.5 \pm 3.7$ & $14.3^{*} \pm 1.3$ & $19.0^{*} \pm 2.1$ \\
$\begin{array}{l}\text { Acetyl CoA } \\
\text { Medium chain }\end{array}$ & $25.8 \pm 1.1$ & $4.87^{*} \pm 0.30$ & $6.20^{*} \pm 0.93$ \\
$\quad$ acyl CoA & $5.40 \pm 0.82$ & $49.9^{*} \pm 4.2$ & $53.8^{*} \pm 5.7$ \\
\hline
\end{tabular}

Means \pm SEM, $n=5-6$.

* Significantly different from acetate-treated rats, $P<0.01$.

There are obvious differences between this model and the hyperammonemia seen in patients with propionic or methylmalonic acidemia. However, in both situations, the CoA derivatives of these organic acids presumably accumulate in liver. The effects we have observed appear to be secondary to this accumulation rather than to the subsequent metabolism of these compounds through the tricarboxylic acid cycle, a process that is severely impaired in such patients but obviously not in normal animals.

Large doses of propionate and methylmalonate were necessary to elicit hyperammonemia in rats given 1.5 $\mathrm{g} / \mathrm{kg}$ of amino acids. However, control animals received the same dosages of acetate. Furthermore, blood levels of propionate close to $5 \mathrm{mM}$ during crises are not unusual in patients with these disorders (30), and the metabolism of these two compounds would be expected to be rapid in normal animals.

After propionate injections, we could detect no abnormalities in the liver that could contribute to hyperammonemia and impaired ureagenesis other than changes directly related to a reduction in carbamyl phosphate synthetase I activity. These changes included lowered $\mathrm{N}$-acetyl glutamate levels, reduced acetyl CoA, and increased medium-chain acyl CoA compounds. Furthermore, the relationship between carbamyl phosphate synthetase I activity of intact mitochondria and liver $\mathrm{N}$-acetyl glutamate content in these animals was identical to that seen in our previous study of rats not administered organic acids (Fig. 5).

These results are consistent with the conclusion that the mechanism of propionate-induced hyperammonemia was a failure of mitochondrial $\mathrm{N}$-acetyl glutamate levels to rise appropriately after injection of amino acids. However, the mechanism for the impaired synthesis of $\mathrm{N}$-acetyl glutamate is uncertain. Neither glutamate, one of the substrates for this enzyme, nor arginine, an activator of the enzyme, changed in whole liver; such data of course do not exclude a redistribution of these amino acids between the cytosolic and mitochondrial compartments.

The accumulated medium-chain acyl CoA derivatives were not identified in this study. Therefore, it is at least theoretically possible that acyl CoA compounds derived from other metabolic pathways may have accumulated, for example, from the metabolism of the branched-chain amino acids administered. Whether such compounds may have inhibited $N$-acetyl glutamate synthesis is unknown. It is more likely that the predominant acyl CoA derivatives were propionyl and methylmalonyl $\mathrm{CoA}$ in the propionate-injected animals. Both of these compounds, as noted above, are competitive inhibitors of $\mathrm{N}$-acetyl glutamate synthetase and, therefore, could have been responsible for the inhibition of $\mathrm{N}$-acetyl glutamate synthesis.

An additional influence on $\mathrm{N}$-acetyl glutamate synthesis must have been exerted by the profound reduction in acetyl CoA, one of the substrates for $\mathrm{N}$-acetyl glutamate synthesis. This fall in acetyl CoA may have been secondary to the diversion of free CoA into medium-chain acyl CoA compounds, which increased many fold. A reduction in acetyl CoA in isolated hepatocytes exposed to $\alpha$-ketoisovalerate was recently demonstrated by Walajtys-Rode et al. (13); at the same time, CoASH fell. If this is the correct interpretation, it is surprising that the fall in acetyl CoA in our experiments was proportionately greater than the fall in CoASH. A complete analysis of the mechanism for these changes would require knowledge of the rates of formation and disposal of acetyl CoA via all pathways.

Another unexplained feature of this aspect of the results is that $\mathrm{N}$-acetyl glutamate levels were unaffected by the lower doses of methylmalonate (10 $\mathrm{mmol} / \mathrm{kg}$; Fig. 4); yet acetyl CoA concentration in the livers of these animals was $14.7 \pm 1.2 \mathrm{nmol} / \mathrm{g}$ wet weight (SEM., $n=5$ ), a value $46 \%$ less than that seen in acetate-injected controls $(27.4 \pm 2.3 \mathrm{nmol} / \mathrm{g}, n=6)$ and $28 \%$ lower than in rats administered no organic acids $(20.4 \pm 1.9 \mathrm{nmol} / \mathrm{g}, n=4)(9)$. Thus, moderate reductions in acetyl CoA do not seem to impair $\mathrm{N}$-acetyl glutamate synthesis. This is surprising, in view of the fact that the mitochondrial concentration of acetyl CoA should be well below the reported Michaelis constant of $\mathrm{N}$-acetyl glutamate synthetase for acetyl CoA, namely 0.6-0.7 $\mathrm{mM}(11,31)$. Propionate at a dose of $10 \mathrm{mmol} / \mathrm{kg}$ reduced acetyl $\mathrm{CoA}$ to $9.9 \pm 0.7 \mathrm{nmol} / \mathrm{g}$ (SEM., $n=5$ ) and did cause hyperammonemia and a fall in $\mathrm{N}$-acetyl glutamate (Fig. 4).

Regardless of the mechanism for the impairment in $\mathrm{N}$-acetyl glutamate synthesis after propionate, it is clear that the rapid increase in hepatic levels of this compound that occur in amino acid-injected rats (9) is important in preventing hyperammonemia. The difference in carbamyl phosphate synthetase I activity between acetate- and propionate-injected rats (Fig. 3) 
was only $\sim 28 \%$, a change that might appear too small to account for the development of hyperammonemia. However, as demonstrated in our previous study (9), increasing loads of amino acids cause little or no rise in blood ammonia in the rat until the capacity of the $\mathrm{N}$-acetyl glutamate mechanism is exceeded; thereafter, ammonia rises steeply. Propionate evidently reduces the threshold dose of amino acids, beyond which this steep increase in blood ammonia occurs. It also has a minor but statistically significant effect on blood ammonia in rats not administered amino acids.

The cause of the hyperammonemia in the rats treated with methylmalonate is more complex. Although an inappropriately low increase in $\mathrm{N}$-acetyl glutamate was demonstrated, differences in citrulline and aspartate levels also suggest that methylmalonate may exert inhibitory effects on arginosuccinic acid synthetase. From the data reported here, the predominant effect cannot be determined with certainty. However, the lower dose of methylmalonate significantly increased liver citrulline without affecting blood ammonia. Furthermore, the relationship between carbamyl phosphate synthetase I activity and $\mathrm{N}$-acetyl glutamate concentrations after methylmalonate injection is the same as in propionate-injected, acetate-injected, or previously studied (9) control animals (Fig. 5). Thus, the most likely explanation of methylmalonate-induced hyperammonemia appears to be inhibition of $N$-acetyl glutamate synthesis through competitive inhibition by methylmalonyl CoA of $\mathrm{N}$-acetyl glutamate synthetase, depletion of mitochondrial acetyl CoA, or both.

Further clarification of these mechanisms in organic acid-injected rats may provide a basis for rational therapy of the hyperammonemia seen in propionic and methylmalonic acidemia.

\section{ACKNOWLEDGMENTS}

The authors thank Valerie Hammond and David Mearns for expert technical assistance.

This work was supported by the Coppleson Foundation of the University of Sydney, Sydney, Australia, and by Program Project grant AM-18020 from the National Institutes of Health.

\section{REFERENCES}

1. Rosenberg, L. E. 1978. Disorders of propionate, methymalonate and cobalamin. In The Metabolic Basis of Inherited Disease. J. B. Stanbury, J. B. Wyngaarden, and D. S. Frederickson, editors. McGraw-Hill, Inc., New York. 4th edition. 21: 411-429.

2. Wolf, B. Y., Y. E. Hsia, K. Tanaka, and L. E. Rosenberg. 1978. Correlations between serum propionate and blood ammonia concentrations in propionic acidemia.J. Pediatr. 93: 971-973.

3. Glasgow, A. M., and H. P. Chase. 1976. Effect of propionic acid on fatty acid oxidation and ureagenesis. Pediatr. Res. 10: 683-686.
4. Glasgow, A. M., and H. P. Chase. 1976. Effect of pent-4enoic acid, propionic acid, and other short-chain fatty acids on citrulline synthesis in rat liver mitochondria. Biochem. J. 156: 301-307.

5. Cathelineau, L., F. P. Petit, F. X. Coude, and P. P. Kamoun. 1979. Effect of propionate and pyruvate on citrulline synthesis and ATP content in rat liver mitochondria. Biochem. Biophys. Res. Commun. 90: 327-332.

6. Bachmann, C. 1974. Urea cycle. In Heritable Disorders of Amino Acid Metabolism. W. L. Nyhan, editor. John Wiley \& Sons, Inc., New York. 361-386.

7. Shigesada, K., and M. Tatibana. 1971. Enzymatic synthesis of acetylglutamate by mammalian liver preparations and its stimulation by arginine. Biochem. Biophys. Res. Commun. 44: 1117-1124.

8. Grisolia, S., and P. P. Cohen. 1953. Catalytic role of glutamate derivatives in citrulline biosynthesis. J. Biol. Chem. 204: 753-757.

9. Stewart, P. M., and M. Walser. 1980. Short-term regulation of ureagenesis. J. Biol. Chem. 255: 5270-5280.

10. Rabier, D., L. Cathelineau, P. Briand, and P. Kamoun. 1979. Propionate and succinate effects on acetyl glutamate biosynthesis by rat liver mitochondria. Biochem. Biophys. Res. Commun. 91: 456-460.

11. Coude, F. X., L. Sweetman, and W. L. Nyhan. 1979. Inhibition by propionyl-coenzyme A of $N$-acetylglutamate synthetase in rat liver mitochondria. J. Clin. Invest. 64: 1544-1551.

12. Gruskay, J. A., and L. E. Rosenberg. 1979. Inhibition of hepatic mitochondrial carbamyl phosphate synthetase I by acyl CoA esters. Possible mechanism of hyperammonemia in organic acidemias. Pediatr. Res. 13: 475. (Abstr.)

13. Walajyts-Rode, E., K. E. Coll, and J. R. Williamson. 1979. Effects of branched-chain $\alpha$-ketoacids on the metabolism of isolated rat liver cells. II. Interactions with gluconeogenesis and urea synthesis. J. Biol. Chem. 254: 111521111529.

14. Scrutton, M. C., and M. F. Utter. 1967. Pyruvate carboxylase. Some properties of the activation by certain acyl derivatives of coenzyme A. J. Biol. Chem. 242: 1723-1735.

15. Halperin, M. L., C. M. Schiller, and I. B. Fritz. 1971. The inhibition by methylmalonic acid of malate transport by the dicarboxylate carrier in rat liver mitrochondria. J. Clin. Invest. 50: 2276-2281.

16. Schimke, R. T. 1962. Adaptive characteristics of urea cycle enzymes in rats. J. Biol. Chem. 237: 459-468.

17. Saheki, T., M. Tsuda, T. Tanaka, and N. Katunuma. 1975. Analysis of regulatory factors for urea synthesis by isolated perfused rat liver. II. Comparison of urea synthesis in livers of rats subjected to different dietary conditions. J. Biochem. (Tokyo). 77: 671-678.

18. Briggs, S., and R. A Freedland. 1976. Effect of ornithine and lactate on urea synthesis in isolated hepatocytes. Biochem. J. 160: 205-209.

19. Rogers, Q., and A. E. Harper. 1965. Amino acid diets and maximal growth in the rat. J. Nutr. 87: 267-273.

20. Lamprecht, W., and I. Trautschold. 1970. Bestimmung mit Hexokinase und Glucose-6-phosphat Dehydrogenase. In Methoden der Enzymatischen Analyse. H. U. Bergmeyer, editor. Verlag Chemie, Weinheim, West Germany. 2nd edition. 2024-2033.

21. Hohorst, H-J. 1970. L-(-)-Malat. Bestimmung mit Malat Dehydrogenase und NAD. In Methoden der Enzymatischen Analyse. H. U. Bergmeyer, editor Verlag Chemie, Weinheim, West Germany. 2nd edition. 1544-1548. 
22. Bergmeyer, H. U., and E. Bernt. 1970. $\alpha$-Ketoglutarat. UV-spektrophotometrische Bestimmung. In Methoden der Enzymatischen Analyse, H. U. Bergmeyer, editor. Verlag Chemie, Weinheim, West Germany. 2nd edition. 1536-1539.

23. Kondrup, J., and N. Grunnet. 1973. The effect of acute and prolonged ethanol treatment on the contents of coenzyme $A$, carnitine and their derivatives in rat liver. Biochem. J. 132: 373-379.

24. McGivan, J. D., N. M. Bradford, and J. B. Chappell. 1974. Adaptive changes in the capacity of systems used for the synthesis of citrulline in rat liver mitochondria in response to low- and high-protein diets. Biochem. J. 142: 359-365.

25. Nicolet, B. H. 1930. Interpretation of the dehydration of acetylglutamic acid by means of glutamylthiohydantoin derivatives. J. Am. Chem. Soc. 52: 1192-1195.

26. Shigesada, K., and M. Tatibana. 1971. Role of acetylglutamate in ureotelism. I. Occurrence and biosynthesis of acetylglutamate in mouse and rat tissues. J. Biol. Chem. 246: 5588-5595.

27. Utter, M. F., and M. C. Scrutton. 1969. Pyruvate carboxylase. Curr. Top. Cell. Regul. 1: 253-296.

28. Siess, E. A., D. G. Brocks, H. K. Lattke, and O. H. Wieland. 1977. Effect of glucagon on metabolite compartmentation in isolated rat liver cells during gluconeogenesis from lactate. Biochem. J. 166: 225-235.

29. Shigesada, K., K. Aoyagi, and M. Tatibana. 1978. Role of acetylglutamate in ureotelism. Variations in acetylglutamate level and its possible significance in mammalian liver. Eur. J. Biochem. 85: 385-391.

30. Hommes, F. A., J. R. G. Knipres, J. D. Eliema, J. F. Jansen, and J. H. P. Jonxis. 1968. Propionic acidemia, a new inborn error of metabolism. Pediatr. Res. 2: 519-524.

31. Shigesada, K., and M. Tatibana. 1978. N-Acetylglutamate synthetase from rat liver mitochondria. Partial purification and catalytic properties. Eur. J. Biochem. 84: 285-291. 